\title{
A Comparative Survey of Vision Metaphors Based on the Corpus in English and Chinese
}

\author{
Zunshuai Li \\ College of Literature and Law, Sichuan Agriculture University, Ya'an, China
}

\begin{abstract}
There are abundant vision metaphorical expressions in both English and Chinese. But past relevant researches were only confined to a single language without a unified and systematic analytical framework. So this paper attempts to collect the vision metaphorical expressions in both English and Chinese so as to conduct a systematic analysis and comparison under a newly-established theoretical framework: Vision Conceptual Metaphorical Mechanism (VCM), which is mainly based on embodied philosophy and also the related theories in Cognitive Linguistics. Through the analysis of the 400 (200 from each language) vision metaphorical expressions, totally 48 vision conceptual metaphors (25 in Chinese and 23 in English) are generalized, which can be further classified into four categories: category of idea, category of judgment, category of expectation and category of behavior. It is concluded that English and Chinese people have lots of universality and diversity in vision conceptual metaphors.
\end{abstract}

Index Terms - embodied philosophy, conceptual metaphor, cognition, VCM, contrast between Chinese and English

\section{INTRODUCTION}

Among the five perceptive senses, vision perception is the most primary one that man uses to know about the world, the result of which is a most important basis for the understanding of the real world. The vision domain is important not only in its own, but also for the production of abstract domains by metaphorical mapping. As a matter of fact, we can easily find that vision metaphors permeate in our daily language.

The contemporary metaphor theory assumes that such conceptual metaphors play a very important role in human cognition, because they are widespread across various cultures. So the study of conceptual metaphors is of great significance.

Therefore, this paper aims to establish VCM mechanism in order to explain the vision metaphorical expressions in both the English and Chinese languages. Briefly, the author conducts the research by ways of collecting the vision metaphorical expressions in both the English and Chinese so as to make a systematic analysis and comparison under VCM, which is mainly based on embodied philosophy and the related theories in Cognitive Linguistics.

In the previous studies in this field, different approaches were used. Nevertheless, few of them used the method of closed corpus. The study made by the thesis is both data-based and theory-based at the same time.

\section{LITERATURE REVIEW}

Leading foreign studies in this field include researches conducted by famous linguists Lakoff \& Johnson, Sweetser and Harald. L \& J (1980, p.50) in their book of Metaphor We Live by proposed that the conceptual metaphor is the basic way for human beings to understand and cognize the world, and they also listed some vision conceptual metaphors, namely: "seeing is knowing", "seeing is touching", "eyes are container for emotion" and "seeing is believing". And they went on to claim in their research that the premised condition for such vision conceptual metaphors is the occurrence of or connection between the target and source domain.

Sweetser further discussed vision metaphorical expressions in English. Sweetser (1990, p.38) in his book From Etymology to Pragmatics held the view that "vision is connected with intellection because it is our primary source of objective data about the world". Harald (2002, p.50) elaborated on vision metaphors involving the visual verb "see" and he summarized that here are four vision conceptual metaphors, namely, "seeing is looking outwardly", "seeing is eating", "seeing is manipulation" and "seeing is attention".

In the past years, many Chinese scholars have also conducted plenty of relevant researches from different perspectives. Through browsing all the publications from 1977 to 2009 in CNKI (China National Knowledge Infrastructure), hundreds of articles concerning conceptual metaphors or the semantic extension of visual concepts can be found, but articles exclusively studying on vision metaphors are deplorably few, not to mention the articles solely related to the contrastive study of Chinese and English vision metaphors.

Qin Xiugui (2008) systematically made a contrastive study of the conceptual metaphor of "eye" in Chinese and English from the perspective of cognitive linguistics. And he found that the domain of "eye" could be mapped onto four experiential domains: domains of intelligence, domains of emotion / attitude, domains of social relation and domains of time or shape. Zhang Xuezhong and Dai Weiping (2007) analyzed the conceptual metaphors related to "eye" and he 
concluded in his article that it is the mapping from our vision domain to other less known domains that allows human beings to reason and understand other less familiar concepts. However, his article lacks adequate and convincing statistics and corpus to support his argument. Wu Xinmin (2006) conducted a contrastive study on Chinese and English conceptual metaphors involving the regularly-used visual verbs. He as well alleged that the domains which our vision concepts map onto are not only domains of mentality, but also domains of the outside physical world, including the social relation domain, and other perceptual domains. Gou Ruilong (2003) discussed the perceptual metaphor system. And he primarily studied on vision metaphors and also their relation with other perceptual domains, so as to prove that there was great iconicity in the creation and use of our daily vision metaphorical expressions.

\section{THEORETICAL BASIS}

In order to solve the deficiency in the previous researches on vision metaphor, this study is going to apply the relevant theories of Cognitive Linguistics to statistically analyze the vision metaphors in the following two chapters.

The solution includes two parts: the theoretical framework and the data analysis. The theoretical basis is constructed from the cognitive theory CM (the Conceptual Metaphor) and it is especially proposed for explaining the vision metaphors in both English and Chinese. Therefore, we temporarily name this theoretical basis as VCM (Vision Conceptual Metaphorical Mechanism) for convenience in the study.

VCM is a sort of a cognitive mechanism or strategy, established on the basis of CM. And as a cognitive mechanism, it is exclusively put forward to explain vision metaphorical expressions in both English and Chinese. By means of VCM mechanism, the predominant vision concepts can be mapped onto other more abstract or less familiar domains, such as domains of behavior, judgment, or expectation.

Specifically, the newly-proposed VCM mechanism incorporates four subcategories of mapping: mapping "from vision to idea", "from vision to judgment", "from vision to expectation" and "from vision to behavior". And in this paper, the author intends to name the four subcategories simply as: "category of idea", "category of judgment", "category of expectation" and "category of behavior" for convenience.

Taken together, the cognitive strategy or mechanism of VCM is mainly composed of the following three leading characteristics besides the common and well-known characteristics of CM:

1. The target domain in VCM is subdivided into four groups according to its own semantic features, namely the "category of idea", "category of judgment", "category of expectation" and "category of behavior".

2. The source domain in VCM is as well divided into two categories: the visual action and the visual organ.

3. VCM displays that the mapping between the target domain and the source domain in a vision metaphorical sentence is actually the mapping from a predominant domain of vision concepts to other less familiar domains, namely domains of idea, judgment, expectation and behaviour. And for the definition of the four categories, please turn to the next chapter for detailed information.

\section{DATAANALYSIS AND DISCUSSION}

400 vision metaphorical sentences (200 Chinese expressions and 200 English expressions) are selected without any bias from the Sketch Engine Website "www.sketchengine.co.uk" to establish the closed corpus for the present study. Vision metaphorical expressions whose target domains are abstract concepts will be divided into four categories according to "four mappings", including mappings "from vision to idea", "from vision to judgment", "from vision to expectation" and "from vision to behavior". And under the four categories, 41 vision conceptual metaphors (21 in Chinese and 20 in English) will be further abstracted from the corpus.

The vision conceptual metaphors in the corpus can be divided into two groups: group of "from concreteness to concreteness" and group of "from concreteness to abstractness". The former refers to the vision conceptual metaphors whose target domains are concrete concepts rather than abstract concepts. Analysis and discussion will not go to the former group because it is only a minor group which only includes a few examples and whose target domains are simple and concrete concepts. The latter involves those vision conceptual metaphors whose target domains are not concrete but more abstract or sophisticated concepts related to one's idea, judgment or expectation. Analysis shows that the former group is a very small group with just a couple of vision conceptual metaphors in both languages whereas the latter group in fact covers most of the vision conceptual metaphors in both Chinese and English corpora and it is, therefore, the center of the present study.

\section{A. From Concreteness to Concreteness}

This small group includes the vision conceptual metaphors whose target domains are concrete concepts such as "hole" or "a leader" instead of abstract concepts. Take the conceptual metaphor of "eye is a hole" in this group as an example. This vision conceptual metaphor involves the projection between a concrete concept "eye" (source) to a concrete concept of "hole" (target). The ground between the source domain and the target domain is the great similarity between the two domains, specifically, their similar shape or appearance.

On the other hand, three vision conceptual metaphors have been abstracted from the English corpus with 8 linguistic expressions, which stand $4.0 \%$ of the total. Both conceptual metaphors of "view/eye is a container" and "eye is a hole" 
have been adopted respectively by three specific metaphorical expressions, which weigh $1.5 \%$ in the English corpus. The "eye is prier" is the least-used vision conceptual metaphor with only 2 linguistic expressions (1.0\%) in the English corpus.

TABLE 1:

VISION CONCEPTUAL METAPHORS IN “FROM CONCRETENESS TO CONCRETENESS”

\begin{tabular}{|l|l|l|c|c|l||}
\hline \hline $\begin{array}{l}\text { Vision Conceptual Metaphor in “from } \\
\text { Concreteness to Concreteness” in the Corpus }\end{array}$ & Number & $\begin{array}{l}\text { Rate } \\
\text { (num /200) }\end{array}$ & Examples \\
\hline Chinese & 1 & 眼是孔洞 & 3 & $1.5 \%$ & 这样的人而欲广交朋友, 岂不等于驼想钻针眼吗? \\
\cline { 2 - 5 } & 2 & 眼是珍贵物 & 3 & $1.5 \%$ & 把钞票当眼珠子看待的, 是工薪族。 \\
\cline { 2 - 5 } & 3 & 眼是打听者 & 2 & $1.0 \%$ & 蛇头大都是黑道上的, 眼线多。 \\
\cline { 2 - 5 } & 4 & 目是首领 & 2 & $1.0 \%$ & 塔利班的指挥官称: 基地头目仍活着。 \\
\hline English & 1 & eye is a container & 3 & $1.5 \%$ & I could see fear in his eyes. \\
\cline { 2 - 5 } & 2 & eye is hole & 2 & $1.5 \%$ & Is it possible for a camel to go through the eye of a needle? \\
\cline { 2 - 5 } & 3 & eye is prier & & Barry is a police man who is now a private eye. \\
\hline
\end{tabular}

However, the group of "from concreteness to concreteness" is not the focus of the present study in that the relation between the source and target in the vision conceptual metaphors in that group is quite simple and obvious. Therefore, efforts will mainly be devoted to the detailed analysis and discussion to the vision conceptual metaphors in the group of "from concreteness to abstractness".

\section{B. From Concreteness to Abstractness}

The group of "from concreteness to abstractness" is the focus of my present study which actually refers to the group of vision conceptual metaphors whose target domains are not concrete but more abstract and intangible concepts related to one's idea, judgment, expectation or behavior. Thus this group is further divided into four subgroups, namely, the category of "from vision to idea", "from vision to judgment", "from vision to expectation" and "from vision to behavior". After the meticulous analysis and computation of the established corpus, information about the four categories of the conceptual metaphors in this group is illustrated very clearly in the following table.

TABLE 2:

VISION CONCEPTUAL METAPHORS IN "FROM CONCRETENESS TO ABSTRACTNESS"

\begin{tabular}{|l|l|l|}
\hline \multirow{2}{*}{ Categories } & Vision Conceptual Metaphors & \multicolumn{2}{l|}{ Number (Rate) } \\
\cline { 2 - 3 } & Chinese & English \\
\hline From vision to idea & $85(42.5 \%)$ & $80(40.0 \%)$ \\
\hline From vision to judgment & $30(15.0 \%)$ & $8 \quad(4.0 \%)$ \\
\hline From vision to expectation & $20(10.0 \%)$ & $24(12.0 \%)$ \\
\hline From vision to behavior & $55(27.5 \%)$ & $80(40.0 \%)$ \\
\hline Total & $190(95.0 \%)$ & $192(96 \%)$ \\
\hline
\end{tabular}

It is found from the table that there exist great similarities between Chinese and English vision conceptual metaphors. In both languages, the category of "from vision to idea" holds the largest share, with 85 vision metaphorical expressions as its specific linguistic instantiation (42.5\%) in Chinese corpus and 80 ones (40.0\%) in its English counterpart, and the category of "from vision to behavior" stands the second largest percentage, with 55 vision metaphorical expressions $(27.5 \%)$ in the Chinese corpus and 80 ones $(40 \%)$ in the English corpus. However, other two categories are somewhat less popular or typical.

It is also worthwhile mentioning that the four summarized categories are by no means separated but closely connected with each other by means of a semantic chain. Therefore, it is of necessity for us to find out their interrelations and the following figure may clearly offer us a glimpse of such a meaning chain between them.



link1: visual observation forms idea link 2: idea ensures judgment making link3: judgment leads to expectation link 4: expectation motivates behavior Figure 1: The semantic chain of the four categories. 
The above figure shows the semantic link between the four categories. And the embodied philosophy can very well provide a cognitive interpretation for such a link between these four different target domains in the four categories in both Chinese and English languages.

And the four categories which will be analyzed and discussed in the following pages also bear such a sequential relationship: from the most dominant vision domain to other less predominant domains.

1. From "vision" to "idea"

Vision is virtually the most leading access to the outside information. Thus, human beings always form their own ideas or always understand the world through their visual observation. Naturally, "vision" and "idea" are interconnected in nature.

2. From "idea" to "judgment"

Once an idea is formed, people may bear or hold a certain impression on or attitude toward a certain entity or situation. And this is called "judgment". A person's "idea" is closely related to "judgment" and indirectly linked to our "vision". Thus, in order to express the two different relations, in the above figure, the line between the "idea" and "judgment" is concrete whereas the line between "vision" and "judgment" is dotted.

3. From "judgment" to "expectation"

One's "expectation" (high or low, positive or negative) is always based on his or her "judgment". Therefore, "judgment" and "expectation" are interrelated with each other. A certain kind of "expectation" of one thing is actually the result of the "judgment" made on it.

4. From "expectation" to "behavior"

One's "expectation" of something may naturally give rise to one's action and movement in order to fulfill his or her "expectations", "dreams" or "hopes". "Expectation" is made in mind, while behavior is realized by a series of plans, preparations and also bodily movements. So it is safe for us to conclude that the former is the driving force for the latter and the latter may also be seen as the result of the former. And as for the relationship between "vision" and "behavior", it is naturally less clear because such a relation is formed at the two far ends of the long semantic chain.

\section{Vision Conceptual Metaphors in the Chinese Corpus}

This section will mainly be devoted to the analysis and discussion of the 200 vision metaphorical expressions in the Chinese corpus under the theoretical framework of VCM.

In Chinese corpus, there are totally 25 vision conceptual metaphors abstracted from 200 vision metaphorical expressions. And the result of the analysis is shown self-evidently in the following table: 
TABLE 3:

VISION CONCEPTUAL METAPHORS IN CHINESE CORPUS

\begin{tabular}{|c|c|c|c|c|}
\hline \multicolumn{2}{|c|}{$\begin{array}{l}\text { Vision Conceptual } \\
\text { Metaphor }\end{array}$} & \multirow{2}{*}{$\begin{array}{l}\text { Number } \\
16\end{array}$} & \multirow{2}{*}{$\begin{array}{l}\text { Rate (num/200) } \\
8.0 \%\end{array}$} & \multirow{2}{*}{$\begin{array}{l}\text { Examples } \\
\text { 从现在看未来, 了解人类从哪里走来。 }\end{array}$} \\
\hline 1 & 看是期待 & & & \\
\hline 2 & 看/视是认为 & 15 & $7.5 \%$ & 他把党与人民的血肉之情看得极重要。 \\
\hline 3 & 看是明白 & 15 & $7.5 \%$ & 他的险恶用心难道你还看不出来吗? \\
\hline 4 & 看是评价 & 13 & $6.5 \%$ & 她对运动员使用兴奋剂一事怎么看? \\
\hline 5 & 看是检查 & 13 & $6.5 \%$ & 村民看小病不出村, 老年人看病免费。 \\
\hline 6 & 看是监控 & 11 & $5.5 \%$ & 他就是看了一辈子井的刘国恩。 \\
\hline 7 & 看喻照顾 & 11 & $5.5 \%$ & 婆婆不替我看宝宝我很伤心。 \\
\hline 8 & 察是调查 & 10 & $5.0 \%$ & 差你往齐东村明察暗访。 \\
\hline 9 & 眼是作证 & 10 & $5.0 \%$ & 让地方公司作眼, 将梁家家财变卖了。 \\
\hline $\begin{array}{l}1 \\
0\end{array}$ & 眼/看是鉴别 & 9 & $4.5 \%$ & 这车子挑的好, 你真有眼力。 \\
\hline \begin{tabular}{l|}
1 \\
1 \\
\end{tabular} & 眼/观/见是观点 & 9 & $4.5 \%$ & 我们要爱勇敢和有远大眼光的人 \\
\hline \begin{tabular}{l|}
1 \\
2
\end{tabular} & 看/见是了解 & 9 & $4.5 \%$ & 城里人要看世界, 农村人也要看世界。 \\
\hline \begin{tabular}{l|}
1 \\
3
\end{tabular} & 看/察是判断 & 8 & $4.0 \%$ & 群众看共产党，还不就是看咱这些共产党干不干实事嘛。 \\
\hline \begin{tabular}{l|}
1 \\
4 \\
\end{tabular} & 眼是注意 & 7 & $3.5 \%$ & 把布告贴在最显眼的地方。 \\
\hline $\begin{array}{l}1 \\
5\end{array}$ & 眼是角度 & 7 & $3.5 \%$ & 以战略的眼光来看待技术管理问题。 \\
\hline \begin{tabular}{l|}
1 \\
6 \\
\end{tabular} & 眼是态度 & 6 & $3.0 \%$ & 我们总是遇到冷眼。 \\
\hline \begin{tabular}{l|l}
1 \\
7
\end{tabular} & 眼/目喻现在 & 6 & $3.0 \%$ & 以后的事以后再说,眼底下的事要紧。 \\
\hline \begin{tabular}{l|l} 
\\
8
\end{tabular} & 眼是要点 & 5 & $2.5 \%$ & 就在节骨眼上,出了奸细, 给官军引路。 \\
\hline \begin{tabular}{l|}
1 \\
9
\end{tabular} & 看是小心 & 4 & $2.0 \%$ & 哪里走, 看打！ \\
\hline \begin{tabular}{l|}
2 \\
0
\end{tabular} & 眼是情感 & 4 & $2.0 \%$ & $\begin{array}{l}\text { 野兽未必肯在享用你以前, 跟你飞眼送秋波, 可方鸿渐不是野兽, } \\
\text { 只算家畜。 }\end{array}$ \\
\hline \begin{tabular}{l|}
2 \\
1
\end{tabular} & 眼是孔洞 & 3 & $1.5 \%$ & 这样的人广交朋友不等于驼想钻针眼吗? \\
\hline \begin{tabular}{l|l}
2 \\
2
\end{tabular} & 眼是珍贵物 & 3 & $1.5 \%$ & 把钞票当眼珠子看待的,是工薪族。 \\
\hline \begin{tabular}{l|l}
2 \\
3
\end{tabular} & 眼是打听者 & 2 & $1.0 \%$ & 蛇头大都是黑道上的, 眼线多。 \\
\hline \begin{tabular}{l|l}
2 \\
4
\end{tabular} & 眼是见识 & 2 & $1.0 \%$ & 快把那几幅名画拿出来,让大家开开眼。 \\
\hline \begin{tabular}{l|}
2 \\
5
\end{tabular} & 目是首领 & 2 & $1.0 \%$ & 塔利班的指挥官称：基地头目仍活着。 \\
\hline
\end{tabular}

Table 3 illustrates very clearly that there are totally 25 vision conceptual metaphors altogether, which are abstracted from the 200 metaphorical expressions in the Chinese corpus. The top five most-used vision conceptual metaphors generally are “看是期待”, “看/视是认为”, “看是明白”, “看是评价” and “看是检查”. The vision conceptual metaphor “看是期待” is adopted by 16 examples (8.0\%) and the “看是认为” conceptual metaphor has 15 specific linguistic expressions (7.5\%), which rank first and second respectively in the Chinese corpus. In Table 4.3, we can also find that both “眼是孔洞” and “眼是珍贵物” have 3 specific linguistic expressions, both of which weigh $1.5 \%$ of the total. “眼 是打听者”, “眼是见识” and “目是首领” are three least-used vision conceptual metaphors. The number of linguistic expressions in each of them is all 2, which stands only $1.0 \%$ of the total in the corpus.

It is also worth mentioning that compared with Table 2.2, 8 new Chinese vision conceptual metaphors have been identified in the corpus, which may be seen as one of the contributions of the present study. And the following shows the additional newly-discovered conceptual metaphors in the Chinese language. 
TABLE 4:

8 NEWLY-IDENTIFIED VISION CONCEPTUAL METAPHORS IN CHINESE CORPUS

\begin{tabular}{|c|c|}
\hline Vision Conceptual Metaphors & Examples \\
\hline 看是期待 & 从现在看未来, 了解人类从哪里走来。 \\
\hline 2. 看是评价 & 她对运动员使用兴奋剂一事怎么看? \\
\hline 看是检查 & 村民看小病不出村, 老年人看病免费。 \\
\hline 察是调查 & 差你往齐东村明察暗访。 \\
\hline 眼是作证 & 让地方公司作眼, 将梁家家财变卖了。 \\
\hline 6. 眼是珍贵之物 & 把钞票当眼珠子看待的,是工薪族。 \\
\hline 7. 眼是角度 & 以战略的眼光来看待技术管理问题。 \\
\hline 8. 目是领导 & 塔利班的指挥官称：基地头目仍活着。 \\
\hline
\end{tabular}

For instance, “眼/看是鉴别能力” means “eyes have judging or appreciating ability”. When people take a look at something or someone, they would unconsciously make a judgment in their minds according to all the information they collect by eyes. That is the basis of the vision metaphorical mapping from vision domain to judgment domain.

(1) 这车子挑的好, 你真有眼力。

(2) 古玩市场也一样，比的是“眼力”。你的眼力好，奇货珍品经常走进你的宝库。

“眼力” in the above two examples refers to the ability in picking out the right commodities. In the given context of market, the meaning of “力” could be metaphorized. During the process of understanding the phrase “眼力”, the mapping happens between the vision domain and mental domain.



In Figure 2, the metaphorical meaning of the "appreciating ability" is achieved through the mapping from attributes like "seeing" and "eye touching" in source domain onto those attributes like "thinking" and "physical touching" in the target domain.

\section{Vision Conceptual Metaphors in the English Corpus}

This part centers on the detailed analysis and discussion of the all the 200 English vision metaphorical expressions and 23 English vision conceptual metaphors abstracted from the vision metaphorical expression in the English corpus under VCM. All the metaphorical expressions whose target domain are abstract concepts are to be divided into four parts which are category of idea, category of judgment, category of expectation and category of behavior.

In the English corpus, the abstracted 23 vision conceptual metaphors are listed clearly in the following table. 
TABLE 5:

VISION CONCEPTUAL METAPHORS IN ENGLISH VISION METAPHORICAL EXPRESSIONS

\begin{tabular}{|c|c|c|c|c|}
\hline \multicolumn{2}{|c|}{ Vision Conceptual Metaphor } & \multirow{2}{*}{$\begin{array}{l}\text { Number } \\
15\end{array}$} & \multirow{2}{*}{$\begin{array}{l}\text { Rate(num/200) } \\
7.5 \%\end{array}$} & \multirow{2}{*}{$\begin{array}{l}\text { Examples } \\
\text { What is your view on school punishments? }\end{array}$} \\
\hline 1 & viewing/eye is opinion/idea & & & \\
\hline 2 & seeing is understanding & 15 & $7.5 \%$ & He didn't see the joke. \\
\hline 3 & seeing is experience & 13 & $6.5 \%$ & London Home Care service saw 103 deaths. \\
\hline 4 & eye is focus of attention & 12 & $6.0 \%$ & He was in the public eye all his life. \\
\hline 5 & seeing is touching & 11 & $5.5 \%$ & I can't take my eyes off her. \\
\hline 6 & eye/sight is knowledge & 11 & $5.5 \%$ & For me it was such an eye-opener. \\
\hline 7 & looking/eye/seeing is thinking & 11 & $5.5 \%$ & Government should look round well before taking measures. \\
\hline 8 & eye is supervision & 10 & $5.0 \%$ & You had better keep an eye on that fellow. \\
\hline 9 & eye is affection & 10 & $5.0 \%$ & John cast sheep's eyes at the new girl. \\
\hline 10 & $\begin{array}{l}\text { eye/seeing/looking/prospecting } \\
\text { is expectation or plan }\end{array}$ & 10 & $5.0 \%$ & Since she left school she's had an eye to marriage. \\
\hline 11 & looking is investigation & 9 & $4.5 \%$ & The mayor promised to look into whether the clash was designed. \\
\hline 12 & seeing is knowing & 9 & $4.5 \%$ & He felt as if John was seeing into his mind. \\
\hline 13 & watching is alerting & 9 & $4.5 \%$ & So please watch your back, you don't know who will hurt. \\
\hline 14 & looking is facing & 8 & $4.0 \%$ & Many new buildings look south. \\
\hline 15 & eye/seeing is judging & 8 & $4.0 \%$ & You do seem to have an eye for essentials. \\
\hline 16 & watching is waiting & 8 & $4.0 \%$ & To watch a chance (an opportunity) need enough patience. \\
\hline 17 & watching is guarding & 7 & $3.5 \%$ & The shepherd is watching a flock of sheep. \\
\hline 18 & view/eye is perspective & 7 & $3.5 \%$ & To my eye, the decoration is excellent. \\
\hline 19 & Seeing is eating & 5 & $2.5 \%$ & Feast your eyes on this beauty \\
\hline 20 & eye is interest & 4 & $2.0 \%$ & She only has eyes for Mark. \\
\hline 21 & eye is hole & 3 & $1.5 \%$ & Is it possible for a camel to go through the eye of a needle? \\
\hline 22 & view/eye is a container & 3 & $1.5 \%$ & I could see fear in his eyes. \\
\hline 23 & eye is prier & 2 & $1.0 \%$ & $\begin{array}{l}\text { Her boyfriend Barry is a former police man who is now a private } \\
\text { eye. }\end{array}$ \\
\hline
\end{tabular}

Table 5 shows that compared with 25 Chinese vision conceptual metaphors, there are only 23 ones abstracted from English corpus. It seems that people in English-speaking countries are a little less skilled at understanding and creating vision metaphorical expressions.

If we compare the above summary with our previous related researches, it is encouraging to see that 8 new vision conceptual metaphors have been identified in the English corpus, which may also be regard as one of the little contributions of the present study. And the following illustrates the additional conceptual metaphors in the English corpus which are actually serving as a complement for the previous achievements.

TABLE 6:

8 NEWLY-IDENTIFIED VISION CONCEPTUAL METAPHORS IN ENGLISH CORPUS

\begin{tabular}{|c|c|}
\hline Vision Conceptual Metaphors & Examples \\
\hline 1. looking is investigation & He promised to look into if the clash was designed. \\
\hline 2. watching is alerting & Please watch your head. \\
\hline 3. looking is facing & Many new buildings look south. \\
\hline 4. eye/seeing is judging & You seem to have an eye for essentials. \\
\hline 5. watching is waiting & To watch a chance need enough patience. \\
\hline 6. watching is guarding & She is watching a flock of sheep. \\
\hline 7. eye is interest & She only has eyes for Mark. \\
\hline 8. eye is hope/wish & Since she left school she's had an eye to marriage. \\
\hline
\end{tabular}

The following is the specific VCM illustration of the more popular vision conceptual metaphor in his group "seeing is understanding".

The visible knowledge collected by eyes is just the perceptual or direct knowledge which is stored in your brain. Only by mental processing in brain, can the superficial and perceptual knowledge become our conceptualized and rational knowledge. The processing of perceptual knowledge in brain is mostly realized by the process of metaphorical mapping.

Such as:

(3) Be around. Like a daughter? Well, you see, that's how I think.

(4) Waited for a young man to find him a cab, I saw my chance.

In (3), "see" means "to understand". When the word "see" is collocated with mental concepts like "think" or "idea", the metaphorical meaning behind the vision verb "see" will be activated. In (4), the concept of "chance" is invisible, but still we can find it by analyzing the situation based on the visible clues. And the following figure shows how the emergent meaning originates. 


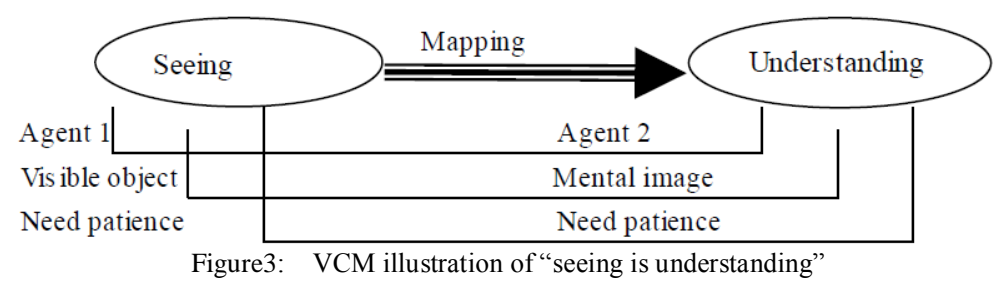

In the process of mapping, parts of the different attributes in the source domain will be projected onto their relative attributes while the similar attributes in both domains will serve as the correlative context. Let take (4) as an example. In the source domain, the "agent 1" of the act will be mapped onto "agent 2" during the projecting process. At the same time the visible object in the source domain will be mapped onto the mental image in the target domain. As we all know that both "seeing" and "thinking" need the patience, time and effort. Here, the patience in both domains will act as the contexts which help us realize the mapping process.

\section{E. Universality of Vision Conceptual Metaphors in Both Languages}

There are 25 vision conceptual metaphors abstracted from the Chinese corpus and 23 ones from the English corpus. Due to the similar living condition in some ways and also the similar cognitive methods or strategies of human beings, commonness of vision metaphors may exist in both languages.

And vision metaphors in English and Chinese share lots of commonness which may originate from the similar embodiment foundation and similar interactive mechanism between human and the outer world. Based on the embodiment foundation and the interaction mechanism, we could find similar conceptualization mechanism of the vision metaphor in both the English and Chinese.

TABLE7:

THE 20 VISION CONCEPTUAL METAPHORS SHARED BY BOTH LANGUAGES

\begin{tabular}{|c|c|c|}
\hline "English Conceptual Metaphors & "Chinese Conceptual Metaphors & Category \\
\hline $\begin{array}{l}\text { 1. eye is idea } \\
\text { 2. eye is hole } \\
\text { 3. eye is container } \\
\text { 4. eye/sight is knowledge } \\
\text { 5. eye is pier } \\
\text { 6. eye is focus of attention } \\
\text { 7. eye/view is perspective } \\
\text { 8. eye/seeing/looking is considering } \\
\text { 9. seeing is thinking } \\
\text { 10. seeing is knowing } \\
\text { 11. seeing is understanding } \\
\text { 12. eye is identifying } \\
\text { 13. seeing is judging } \\
\text { 14. eye/seeing/looking is expectation } \\
\text { 15. eye is affection/interest } \\
\text { 16. seeing is experiencing } \\
\text { 17. seeing is evaluating } \\
\text { 18. eye is supervision } \\
\text { 19. watching is guarding } \\
\text { 20. looking is investigation }\end{array}$ & $\begin{array}{ll}1 . & \text { 眼/观/见是观点 } \\
2 . & \text { 眼是孔洞 } \\
3 . & \text { 眼是容器 } \\
4 . & \text { 眼是见识 } \\
\text { 5. } & \text { 眼是打听者 } \\
6 . & \text { 眼是注意 } \\
\text { 7. } & \text { 眼是角度 } \\
8 . & \text { 看是认为 } \\
\text { 9. } & \text { 看是思考 } \\
10 . & \text { 看见是了解 } \\
11 . & \text { 看是明白 } \\
12 . & \text { 眼是鉴别 } \\
13 . & \text { 看是判断 } \\
14 . & \text { 看是期待 } \\
15 . & \text { 眼是情感 } \\
16 . & \text { 看是经历 } \\
17 . & \text { 看是评价 } \\
18 . & \text { 看是监控 } \\
19 . & \text { 眼是照顾 } \\
20 . & \text { 察是调查 }\end{array}$ & $\begin{array}{l}\text { idea } \\
\text { idea } \\
\text { idea } \\
\text { idea } \\
\text { idea } \\
\text { idea } \\
\text { idea } \\
\text { idea } \\
\text { idea } \\
\text { idea } \\
\text { idea } \\
\text { judgment } \\
\text { judgment } \\
\text { expectation } \\
\text { expectation } \\
\text { behavior } \\
\text { behavior } \\
\text { behavior } \\
\text { behavior } \\
\text { behavior }\end{array}$ \\
\hline
\end{tabular}

The above table summarized shows that most of the vision conceptual metaphors shared by both Chinese and English are in the first category of idea. There are totally 11 shared vision conceptual metaphors whose target domains are all related to the concept of "idea or thinking". Embodied philosophy may perfectly well afford us an interpretation for such phenomenon: human beings more often employ the familiar concepts of vision to say the abstract concepts of idea in that "vision" and "idea" have developed or established a very strong connection in the process of our cognization of the world.

And given the analysis above, commonness shared by both languages can be illustrated as follows:

1. Physiological research shows that all human beings' vision perception depends on three factors: (1) the structure of the eye; (2) the vision stimulus (light); (3) the pathway from the eye to the brain.

Such as:

(5) 吴伯雄九十六岁高龄的父亲吴鸿麟老先生看在心里, 感到非常的同情。

(6) 会看的看门道, 不会看的看热闹。

(7) Waited for a young man to find him a cab, I saw my chance.

(8) Be around. Like a daughter? Well, you see, that's how I think.

In example (5), “看在心里” means “to have a deep impression”. Every day, we may collect a great deal of vision 
information through our eyes. However, only a very little segment of them can be reserved or locked in our brain. The vision verb "看” here is obviously to emphasize the outline of what is seen.

2. Cognitive psychological research shows that the development of human cognition is a process from concrete to abstract, from known to unknown, which actually is the basis for adopting the cognitive strategies of metaphor and metonymy when we are describing something new or complicated. Although we have five sensors to obtain concrete knowledge from the world we live in, vision perception is the most important and primary channel.

3. Most activities of human beings are to deplore and understand their outside objective and complicated world. The outside world which provides the environment and living necessities for human beings are quite similar or almost the same since we share the same earth and natural resources. That is the reason why both Chinese people and the English-speaking people are very apt at understanding and creating many metaphorical expressions to describe our similar lifestyle or activities with a similar strategy of VCM.

\section{F. Diversity of Vision Conceptual Metaphors in Both Languages}

This part also functions as the complementary part of the all-round analysis of vision metaphors in the present study. And we will elaborate on the variations between the vision metaphors by a summarized table.

And the following summarized table can show us a sketch of the diversity of vision conceptual metaphors in both languages. Specifically, the table above affords us the specific conceptual metaphors which are unique in Chinese or English vision metaphorical expressions.

TABLE 8:

UNIQUE VISION CONCEPTUAL METAPHORS IN BOTH LANGUAGES

\begin{tabular}{|l|l||}
\hline English Conceptual Metaphors & Chinese Conceptual Metaphors \\
\hline 1. seeing is eating & 1. 眼是珍贵物 \\
2. looking is facing & 2. 眼底/目前/眼前喻现在 \\
3. watching is waiting & 3. 目是首领 \\
& 4 . 看是体检 \\
& 5. 眼是作证 \\
\hline
\end{tabular}

The above table shows the unique vision conceptual metaphors in Chinese and English. Based on the analysis of the two corpora, 3 unique vision conceptual metaphors in English language and 5 ones in Chinese languages have been identified altogether. Also in some other cases, English and Chinese may share the same conceptual metaphors but with different metaphorical manifestations. In other words, the linguistic instantiation of the same conceptual metaphor varies.

And the author believes the reasons for this difference lie in the following two contributors: 1) different cultural values; 2) different living conditions.

1. Cultural values are different. Cultural anthropologists often investigate the ways that experience is understood differently in different cultures.

English and Chinese are two different languages belonging to and as well reflecting different eastern and western cultures. Culture influences human being's experience and cognitive model and thus gives rise to different conceptual metaphorization of vision terms. So the diversity in language actually is an embodiment of culture conflict.

2. Living conditions are different. Different living conditions may produce different experiences. It is based on these experiences that a variety of vision metaphorical expressions could be generated. Due to the different experiences, the selection of the concepts in both source domains and target domains may vary. Thus we have different vision metaphorical expressions in English and Chinese languages.

(9) 姚明轻看中国男篮亚运对手直言韩国队夺冠没戏。

(10) The on-lookers see through most of games.

In the above examples, vision verbs "看" and "see" are combined with those adjectives and prepositions which express physical concept such as "轻”, "through". It seems that Chinese people tend to treat vision concept as entity and believe that the meaning of vision verbs and vision nouns should have some features of entity. Such as “重” or “轻” and later we have “轻视” and “重视”. However, English people prefer to take concepts of space as the target domains. Thus we have "look up to" or "look down upon" or "look through" in English language.

1) “眼是珍贵物” is the particular vision conceptual metaphor in Chinese corpus with 3 vision metaphorical expressions, which stand $1.5 \%$ of the total. Eye is the most indispensable organ for human beings. Without vision organ, we would live in darkness forever. So that we cherish it, love it and try to protect it as well as possible. Eye is like the gift bestowed by our parents. Based on the similarity, a metaphorical projecting between "vision organs" and "cherished materials" come into being.

2) "Watching is facing" is also a unique vision conceptual metaphor never shared by Chinese expressions. Actually, in Chinese, people can only use “面朝, 面对” to express the meaning of facing a certain direction, whereas in English, such meaning can be expressed feasibly in two different concepts of "facing" and "watching".

3) "Watching or looking is waiting" is as well a very unique vision conceptual metaphor in English. And in Chinese, we have not identified such kind of vision conceptual metaphors so far. In the conceptual of "watching is waiting", 
waiting is action involving many specific acts such as watching, listening, and expecting.

(11) He watched to see what I would do.

(12) He watched for his chance to propose to her.

"Looking or watching is facing" certainly comes from our daily bodily experience. But such an experience is more impressive for the English people. For Chinese people who pay much more attention to their value of "face", they may only use "面" to mean "face" and that is why we only find in English corpus the existence of the vision conceptual metaphor of "looking or watching is facing" but not in Chinese.

\section{CONCLUSION}

\section{A. Contributions of the Thesis}

In conclusion, the significance and contributions in the present study are listed as follows:

1. Based on the reflection of the theories of metaphor, including the vision conceptual metaphors, the author proposes VCM mechanism for the first time.

2. The author makes a comprehensive survey on 14 vision vocabularies (7 in Chinese and 7 in English), establishes a closed corpus with 400 examples, and attempts to compare and analyze their similarities and differences systematically, with some relevant data and proportions. Through comparison, this research reveals that vision metaphors show some universalities and diversities between English and Chinese.

3. Analysis of the corpus unfolds some important findings: totally 48 conceptual metaphors being abstracted from the corpus (25 in Chinese, 23 in English); the top three in Chinese and English vision conceptual metaphors are respectively (cf. p. 25 \& p. 36): “看是期待(16)”, “看/视是认为 (15)” and “看是明白 (15)”, “Viewing/eye is opinion/idea (15)”, "seeing is understanding (15)" and "seeing is experience (13)". And also in both corpora the categories of idea hold the largest percentage with $42.5 \%$ and $40.0 \%$ in both Chinese and English languages.

4. 16 vision conceptual metaphors ( 8 in Chinese and 8 in English corpora respectively) have been added to the summarized vision conceptual metaphors in the previous researches.

In general, the empirical studies presented herein reinforce the view that metaphor is the main mechanism through which human beings comprehend abstract concepts and perform abstract reasoning. These conceptual metaphors are grounded in our basic human experiences that may be universalities to all human beings.

\section{B. Limitations and Suggestions for Further Study}

So far, the basic goal of this study has been fulfilled: to sort out the cognitive foundation of metaphor and to provide cultural explanations to the universalities and diversities from the comparative perspective between English and Chinese linguistic data. By this it does not mean that the current research is exhaustive and all-inclusive. Instead, from a macro-level perspective, the studies presented in this thesis are still very limited in breadth and depth.

And also VCM, especially proposed for this study, may also prove to be of great use when applied and extended to explanation of other perception conceptual metaphors.

\section{REFERENCES}

[1] Aristotle. (1954). Rhetoric and poetics. New York: The Modern Library.

[2] Black, M. (1979). More about metaphor. In A.Ortony (Ed.), Metaphor and thought. New York: Cambridge University Press.

[3] Harald. (2002). What language reveals about our conceptions: A case study on seeing. Cognitive Linguistics, (12), 49-51.

[4] Kövecses, Z. (2002). Metaphor: A practical introduction. Oxford: Oxford University Press.

[5] Kripke, S. (1980). Naming and necessity .Oxford: Blackwell.

[6] Lakoff, G. \& Johnson, M. (1980). Metaphors we live by. Chicago: University of Chicago Press.

[7] Reddy, M. (1979). The conduit metaphor: A case of frame conflict in our language about language. In A. Ortony (Ed). Metaphor and thought (pp. 284-324). Cambridge: Cambridge University Press.

[8] Richards, I. A. (1936). The philosophy of rhetoric. Oxford: Oxford University Press.

[9] Sweetser, E. (1990). From etymology to pragmatics: Metaphorical etymology to pragmatics. Cambridge: Cambridge University Press.

[10] Jia Chen. (2003). A Comparative Study of Conventional Vision Metaphors between English and Chinese. Journal of PLA University of Foreign Languages, (1), 20-23.

[11] Weiping Dai. (2006). The Mental, Metaphors of English Vision Words. Guangxi Social Science, (2), 54-56.

[12] Yuan Gao, Fuyin Li. (2005). Ten Lectures on Cognitive Linguistics by George Lakoff. Beijing: Foreign Language Teaching and Research Press.

[13] Ruilong Gou. (2003). The Methorical System of Chinese Sensitive Categories. Journal of Zhengzhou University, (5), 54-55.

[14] Xiugui Qin. (2008). The Study on Olfactory Metaphors and Their Projecting Range in English and Chinese. Foreign Language Teaching and Research, (1), 16-18.

[15] Lingling Zeng. (2008). A Comparative Study on Conceptual Study between English and Chinese. Journal of Zhejiang Wanli University, 2008, (06), 16-19.

[16] Yueli Wang, Kunpeng Ni. (2008). A Survey of Semantic Extension from the Aspect of Cognitive Mode of Metaphor and Metonymy. Journal of Leshan Normal University, (2), 52-58.

[17] Xuezhong Zhang, Weiping Dai. (2007). The Metaphorical Analysis on “Eye”. Guangxi Social Science, (10), 33-36. 
[18] Hongjuan Sun, Hongbo Zhao. (2007). A Comparative Study on Metaphors of "Eye" in English and Chinese. Application of languages and Characters, (1), 22-26.

[19] Xinmin Wu. (2006). A comparative Study on Conceptual Metaphors between Chinese and English Vision Verbs. Journal of Jining University, (4), 56-59.

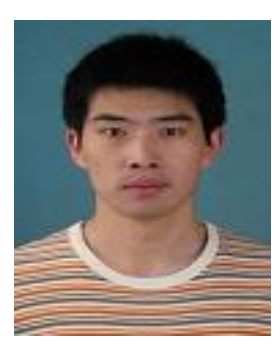

Zunshuai Li, (Han Zu) 35, is a lecturer teaching English language in English department of Sichuan Agriculture University.

He attained his MA degree of Foreign and Applied Linguistics in Sichuan International Study University in China. He has interested in Cognitive Linguistics and Culture Study. His birth place is Jining, Shandong Province. 